\title{
Impact of Intellectual Disability on the Family Economy in Calabar, Cross River State, Nigeria
}

\author{
Owoade Philip Adeleke*, James Abua Ewa, James Eburikuri Olayi and Samuel Orim Orim
}

\author{
Department of Special Education, University of Calabar, Calabar, Nigeria
}

\begin{abstract}
This study investigated the impact of intellectual disability (ID) on the family economy in Calabar, Cross River State, Nigeria. The cost of parenting a child with ID in Nigeria is overwhelming as there is no state provision for the care of this group, consequently imposing burden on the parents. Parents of persons with ID in Calabar South Local Government Area, Cross River State, Nigeria, constituted the study population. The study sample includes 150 parents of persons with ID. Intellectual Disability and Family Economy Assessment Scale $(r=0.877)$ was used for data collection. Data were analysed using frequency count and percentage. The study revealed that ID significantly affects the family economy and education of siblings and persons with ID in Calabar, Cross River State, Nigeria. The impact of ID on the family economy in the study area is generally negative. Nigerian government should put in place the necessary social facility that will help reduce the impact of the disability on the families.
\end{abstract}

Keywords: Intellectual disability (ID), impact, family economy, Calabar, Nigeria.

\section{INTRODUCTION}

Intellectual disability (formerly called mental retardation) is characterized by below-average intelligence and a lack of skills necessary for daily living. The disability is characterized by the impairment of cognition, which leads to significant limitations in the development of skills necessary for daily life activities. It manifests during the developmental period. Impact, according to the advanced learner's dictionary, is defined as a significant or strong influence, an effect. Children with ID are those who fall below the percentage of 70 when the intelligence quotient (I.Q) is being measured using an I.Q test. Those who scored below 70 in the standard test are considered to have ID. Individuals with ID show deficits relative to other children of that age, in at least two of some specific skills areas; communication, self-care, home living, social or interpersonal, use of community resources, self-direction, works, leisure, health and personal safety $[1,2]$.

The life management of children with ID requires parental commitment. For many years, the child with ID in Nigeria has been a source of disappointment, unhappiness, and regret because of the societal belief system, attitudinal disposition, and lack of service for these individuals and their family members. There is ignorance on the part of Nigerians about children with ID leading to human rights abuses, discriminations, lack of social acceptance, and general negative attitude to the child and the family - the categories of children with ID range from the mild to profound and each with

*Address correspondence to this author at the Department of Special Education, University of Calabar, Calabar, Nigeria;

E-mail: mafikuyomiphilip@yahoo.com its distinctive difficulties. Having a family member with ID can cause a severe negative turn around on the entire family, the parents, siblings, and extended family members. The disability has its effects through the time and functional costs, physical and emotional demands, and logistic complexities associated with caring for the affected child. It may increase stress, take a toll on physical and mental health, make it challenging to find appropriate and affordable child care, and affect decisions about work, education/training, having additional children, and relying on public support. It may be associated with guilt, blame, or reduced selfesteem. Out-of-pocket medical care and other services may be enormous [3-5].

It equally has a significant social and economic impact, particularly on the family psychologically. It may cause discrimination from the general society, extra financial cost for the family because of a lack of free health services, and appropriate social services for this group, especially in Nigeria. This may have a gross impact on the society as children/persons with ID may not be able to contribute their quota to the society, thereby making the dependency ratio to be on the high level. Families and individuals with ID have higher tendencies to experience poverty twice as that of those without a disability. Disability and poverty are a dangerous combination capable of causing severe suffering for the family members and persons with ID [6]. Individuals with mild ID and supporting family members have tendencies to experience poverty and belong to low social class [7]. As a result of discrimination, many people with ID have difficulties gaining employment. There is a significant association between the prevalence of ID and family poverty. Poverty can cause intellectual disability, resulting in the 
inability to make provision for needed services or life necessities. Families supporting a child with ID are at risk of experiencing poverty due to the financial and social impact of caring for the child.

The presence of a child with ID in the family is generally a source of concern for the family members. The cost implication of having a child with ID is endless. The impact, equally, mostly depends on the level of severity of the disability. As the presence of children with ID leads to poverty, poverty has also been implicated as one potential cause of the disability. It does so through a lack of financial ability to access good health and necessary information that can help in the prevention of the disability. There has been a growing concern over the parenting of children with ID due to poverty. Besides, children with ID are likely not to get proper education, medical services, shelter, clothing, and social attention needed as expected by the parents.

Emerson and Parish [8] also observed that there is a relationship between ID and low family income. Emerson [9] reported that people with less severe intellectual disability, and the families that support them, are much more likely to be located in lower socioeconomic positions and to experience poverty. It has equally been concluded that there is significant financial vulnerability among US parents of children with ID [8]. Emerson [10] and Van Cleave, Gortmaker and Perrin [11] explained that low income is of considerable relevance to ID as young people with ID are at higher risk than their non-disabled peers in experiencing poverty, the experience of poverty is likely to be associated with poor parental health and well-being and consequently poorer parenting practices and associated with poor child health and well-being and that those that grow up in poverty are less likely to be treated for their conditions, as they generally have more limited access to care while those with insurance may face additional barriers and leading to poorer health outcomes. Simkiss, Blackburn, Felix, et al. [12] emphasised that the majority of children with disabilities live in low and middle income.

The education of the siblings of persons with ID is often affected by the disability in the family. According to Roth, Barson, Hoekstra, Pasco, and Whatson [13], the experience of siblings of children with autism varies from family to family. She maintained that certain factors might compound the difficulties for siblings. For instance, when a family is affected by other factors such as low income or limited leisure opportunities, or stress on the parents. Study according to Barak-Levy, Goldstein, and Weinstock [14], as reported by Ashley [15], indicated siblings of individuals with disabilities had been found to participate in fewer extracurricular activities than their peers. Marks, Matson, and Barraza [16] found that siblings have a desire to make improvements in the areas of services provided to individuals with disabilities. In most cases, it is discovered that the inability of most parents to provide needed education services for their children with ID, usually affects their siblings' careers equally. Relative to this, the result of the study by Marks et al. [16], revealed that when the sibling without a disability has responsibility for the brother or sister with a disability, there can be a positive impact such as leading them to select a profession related to improving practices for individuals with disabilities.

\section{Objectives of the Study}

The main objectives of this study are to assess:

1. The impact of ID on the economy of the family in Calabar, Cross River State, Nigeria.

2. The impact of ID on the education of the siblings in Calabar, Cross River State, Nigeria.

3. The impact of ID on the access to quality education for persons with ID in Calabar, Cross river state. Nigeria.

\section{METHOD}

\section{Design}

The simple survey research design was adopted to assess the impact of intellectual disability on the family economy in this study.

\section{Study Participants}

One hundred and fifty parents of children with ID were selected based on their availability and personal consent. The selection was made through the Special Education Centre, Ibom Layout, Calabar (being the only school that accommodates individuals with intellectual disabilities in Cross River State). Based on the societal attitude towards persons with ID and their families, the ethical responsibility of confidentiality was assured and maintained. 


\section{Study Variables}

Variables include intellectual disability, which is independent while the family economy is the dependent variable.

\section{Instrument}

A self-designed rating scale was used (Intellectual Disability and Family Economy Assessment Scale) for data collection. The instrument contained twenty items on parents' opinions on the impact of ID on their family economy. It was dully validated, and the reliability value, using Cronbach Alpha, was $r=0.877$.

\section{Analysis}

Descriptive statistics, including; frequency count, percentage, mean and standard deviation, were used for data analysis.

\section{RESULT}

The result in Table 1 indicates that 59 (39.3\%) of the respondents agree that their employment is affected by the ID of children. $64(44.7 \%)$ agree that ID of their children affects their business adversely. 64 $(42.7 \%)$ agree that they cannot get gainful employment because of the disability in their family. 95 (45.5\%) agree their family saving is affected because of the ID of their children. $52(34.7 \%)$ agree that the ID of their children affected their business trips. From this result, the majority of respondents agree that the presence of a child with ID in their family affects their employment.
By implication, ID affects the economy of the parents significantly, which indicates there is a relationship between the presence of ID and poverty in the family.

Table 2 shows that $55(36.7 \%)$ strongly agree that a lack of money affects the education of other children in the family. $71(41.3 \%)$ strongly agree that lack of funds makes it impossible for them to buy necessary textbooks for the education of other children in the family. $50(33.3 \%)$ strongly agree that the lack of money makes it difficult for them to purchase proper school uniforms for other children. $82(54.7 \%)$ strongly agree that they cannot afford private education for other children because of a lack of money. 53 (35.4\%) agree that they cannot send their children to private schools because of a lack of funds. This result indicates that the education of siblings of children with ID is negatively affected.

Table 3 shows that $74(49.3 \%)$ strongly agree that they cannot send their children with ID to a special private school because of low income. 53 (35.3\%) strongly agree that they cannot have private home teachers for the children with ID because of low income. $58(38.7 \%)$ strongly agree that their children with ID cannot be given early intervention because of low income in the family. $57(38.0 \%)$ strongly agree that they cannot afford rehabilitation services for their children with ID because of low income. 56 (37.3\%) strongly agree that their children with ID cannot go for standard educational screening and assessment because of low income. From this result, it is clear that low income harms the education of children with ID.

Table 1: Showing Simple Percentage, Mean, Frequency Count and Standard Deviation on the Impact of ID on Family Economy

\begin{tabular}{|c|c|c|c|c|c|c|c|c|}
\hline$S / N$ & VARIABLES & $\mathbf{N}$ & $\begin{array}{l}\text { Strongly } \\
\text { Agree SA } \\
\text { (\%) }\end{array}$ & $\begin{array}{c}\text { Agree A } \\
(\%)\end{array}$ & Disagree $\mathrm{D}(\%)$ & $\begin{array}{l}\text { Strongly } \\
\text { Disagree } \\
(\%)\end{array}$ & Means & SD \\
\hline 1. & $\begin{array}{l}\text { My employment is affected by } \\
\text { the presence of a child with } \\
\text { an intellectual disability in the } \\
\text { family }\end{array}$ & 150 & $\begin{array}{c}59 \\
(39.3)\end{array}$ & $\begin{array}{c}41 \\
(27.3)\end{array}$ & $\begin{array}{c}40 \\
(26.7)\end{array}$ & $\begin{array}{c}10 \\
(6.7)\end{array}$ & 2.99 & 0.966 \\
\hline 2. & $\begin{array}{l}\text { The disability of my child } \\
\text { affects my business adversely }\end{array}$ & 150 & $67(44.7)$ & $34(22.7)$ & $31(20.7)$ & $\begin{array}{c}18 \\
(12.0)\end{array}$ & 3.00 & 1.068 \\
\hline 3. & $\begin{array}{c}\text { Because of my child's } \\
\text { disability, I cannot get a good } \\
\text { job }\end{array}$ & 150 & $\begin{array}{c}64 \\
(42.7)\end{array}$ & $\begin{array}{c}44 \\
(29.3)\end{array}$ & $\begin{array}{c}20 \\
(13.3)\end{array}$ & $\begin{array}{c}22 \\
(14.7)\end{array}$ & 3.00 & 1.074 \\
\hline 4. & $\begin{array}{l}\text { Because of my child's } \\
\text { disability, I cannot safe much } \\
\text { money }\end{array}$ & 150 & $\begin{array}{c}95 \\
(63.3)\end{array}$ & $\begin{array}{c}40 \\
(26.7)\end{array}$ & $\begin{array}{c}10 \\
(6.7)\end{array}$ & $\begin{array}{c}5 \\
(3.3)\end{array}$ & 3.50 & 0.766 \\
\hline 5. & $\begin{array}{l}\text { Because of my child's } \\
\text { disability, I cannot go on } \\
\text { business trips }\end{array}$ & 150 & $\begin{array}{c}52 \\
(34.7)\end{array}$ & $\begin{array}{c}50 \\
(33.3)\end{array}$ & $\begin{array}{c}41 \\
(27.3)\end{array}$ & $\begin{array}{c}7 \\
(4.7)\end{array}$ & 2.98 & 0.901 \\
\hline
\end{tabular}


Table 2: Simple Percentage, Mean, Frequency Count and Standard Deviation on ID and Education of the Siblings

\begin{tabular}{|c|c|c|c|c|c|c|c|c|}
\hline $\mathbf{S} / \mathbf{N}$ & VARIABLES & $\mathbf{N}$ & $\begin{array}{l}\text { Strongly } \\
\text { Agree SA } \\
(\%)\end{array}$ & $\begin{array}{c}\text { Agree } A \\
(\%)\end{array}$ & $\begin{array}{c}\text { Disagree D } \\
(\%)\end{array}$ & $\begin{array}{c}\text { Strongly } \\
\text { Disagree SD } \\
(\%)\end{array}$ & Means & SD \\
\hline 1. & $\begin{array}{l}\text { Lack of money affects the } \\
\text { education of my our children }\end{array}$ & 150 & $\begin{array}{c}55 \\
(36.7)\end{array}$ & $52(34.7)$ & $\begin{array}{c}37 \\
(24.7)\end{array}$ & $\begin{array}{c}6 \\
(4.0)\end{array}$ & 3.04 & 0.881 \\
\hline 2. & $\begin{array}{l}\text { Lack of money makes it difficult to } \\
\text { buy necessary textbooks for my } \\
\text { children education }\end{array}$ & 150 & $\begin{array}{c}71 \\
(47.3)\end{array}$ & $44(29.3)$ & $\begin{array}{c}24 \\
(16.0)\end{array}$ & $\begin{array}{c}11 \\
(7.3)\end{array}$ & 3.17 & 0.951 \\
\hline 4. & $\begin{array}{l}\text { We cannot buy/afford necessary } \\
\text { educational resources for our } \\
\text { children because of lack of money }\end{array}$ & 150 & $\begin{array}{c}82 \\
(54.7)\end{array}$ & $46(30.7)$ & $\begin{array}{c}10 \\
(6.7)\end{array}$ & $\begin{array}{c}11 \\
(7.3)\end{array}$ & 3.36 & 0.943 \\
\hline
\end{tabular}

Table 3: Simple Percentage, Mean, Frequency Count and Standard Deviation on ID and Education of the Children with Intellectual Disability in Cross River State, Nigeria

\begin{tabular}{|c|c|c|c|c|c|c|c|c|}
\hline$S / N$ & VARIABLES & $\mathbf{N}$ & $\begin{array}{l}\text { Strongly } \\
\text { Agree SA } \\
\text { (\%) }\end{array}$ & $\underset{(\%)}{\text { Agree A }}$ & $\begin{array}{c}\text { Disagree } D \\
(\%)\end{array}$ & $\begin{array}{l}\text { Strongly } \\
\text { Disagree } \\
\text { SD (\%) }\end{array}$ & Means & SD \\
\hline 1. & $\begin{array}{l}\text { We cannot send our child with ID to } \\
\text { private school because of lack of } \\
\text { money }\end{array}$ & 150 & $74(49.3)$ & $48(32.0)$ & $21(14.0)$ & $\begin{array}{c}7 \\
(4.7)\end{array}$ & 3.26 & 0.870 \\
\hline 2. & $\begin{array}{l}\text { We cannot afford private therapists for } \\
\text { our child with ID because of lack of } \\
\text { money }\end{array}$ & 150 & $53(35.3)$ & $51(34.0)$ & $34(22.7)$ & $\begin{array}{c}12 \\
(8.0)\end{array}$ & 2.97 & 0.951 \\
\hline 3. & $\begin{array}{l}\text { Our child with I.D cannot get early } \\
\text { intervention because of lack of money }\end{array}$ & 150 & $58(38.7)$ & $52(34.7)$ & $28(18.7)$ & $\begin{array}{c}12 \\
(8.0)\end{array}$ & 3.04 & 0.947 \\
\hline 4. & $\begin{array}{l}\text { We cannot afford rehabilitation } \\
\text { services for our child with ID because } \\
\text { of lack of money }\end{array}$ & 150 & $57(38.0)$ & $\begin{array}{c}46 \\
(52)\end{array}$ & $22(14.7)$ & $19(12.7)$ & 2.98 & 1.020 \\
\hline
\end{tabular}

\section{Summary of Findings}

1. ID has a significant negative impact on the economy of a family of persons with ID in Calabar, Cross River State, Nigeria.

2. ID has a significant negative impact on the education of siblings of persons with ID in Calabar, Cross River State, Nigeria.

3. ID in the family has a significant negative impact on the access to quality education of persons with ID in Calabar, Cross River State, Nigeria.

\section{DISCUSSION}

Impact of Intellectual Disability on the Economy of the Family in Calabar, Cross River State

The finding of this study revealed that ID has a significant effect on the economy of the family in Calabar, Cross River State. ID is the most challenging disability and most impactful, in most cases, negatively. According to results, it implies that the presence of ID impacts negatively on the overall economy of the family. Most of the respondents indicated that their employment is affected by their children's ID, 81.8\%). 
The disability of their children affects their business adversely (63.5\%). They cannot get gainful employment because of the ID in their family (63\%). Family saving is affected because of the ID of their children $(78.8 \%)$. ID of their children affected their business trips $(78.8 \%)$.

The finding of this study is in line with the results of research work reported by Emerson and Parish [8], who discovered that there is a relationship between ID and low income in the family. Emerson [9] also reported that people with less severe ID, and the families that support them, are much more likely to be located in lower socioeconomic positions and to experience poverty. ID is a severe disability that always affects every area of family life. The reason is that most persons with ID are generally prone to sickness, consequently causing the family much to maintain the health of such a child. It equally affects the source of income for the family as either of the two parents is likely to lose a job, which will automatically reduce the family's financial ability. Emerson and Parish [8] finds that there is significant economic vulnerability among US parents of children with ID. Another factor related to the impact of ID on the family economy is the effect on family cohesion. Most of the respondents in this study are single parents, mostly mothers whom their husbands have separated from them because of the child's birth with ID. This also consequently impact on the ability to generate needed income by the suffering and lonely mother that will need to fend for other children equally.

Several factors may account for the poverty level of a family of persons with ID. Roth et al. [13] stated that ID has an enormous impact on the family economy as parents have to make accommodations for extra things for a child with ID. Emerson and Parish [8] identified income-poverty and limited savings as significant poverty factors among US parents caring for children with ID, and these cause them to be financially vulnerable in most cases. Parenting a child with ID or any other developmental disability is generally demanding because of the associated services the child may require to live an average independent life. Batul [17] found that families of children with ID are affected by poor financial conditions because more is required to raise a child with ID with little prospect of the child earning a living of his/her own in later life. Most individuals with ID need a multidisciplinary approach and a series of services to develop skills required for independent living with high financial implications on their parents, thereby affecting the family economy. This is further made complicated because of a lack of social facility, especially in Nigeria, to assist parents in caring for individuals with disabilities.

A study by Mu'ala, Abas, and Shawam [18] discovered that $28.3 \%$ of the mothers have to stop work because of the burden of care, meeting the needs/supervision of their children with ID, hence reducing the family income. Emerson [10], in confirmation, discovered that mothers of children with intellectual disabilities experience poor socio-economic status compared to mothers of typically developed children. Parents in paid work have to take off time to care for their children with ID. Financial stress, employment loss, and overall negative economic impact are common in families with a severely disabled child $[3,4]$. Research shows that parents reported that caring for the intellectually disabled child is demanding, as some cannot engage in their economic activities because of the child's problem. Some, if they had to engage, would have to employ a caretaker for the child, and that causes the out-pocket expenses.

\section{The Impact of ID on the Education of Siblings of Children with ID in Cross River State}

This study revealed that ID has a significant impact on the education of siblings of children with ID in Calabar, Cross River State. Lack of money affects the education of other children in the family $(90.0 \%)$. Lack of funds makes it impossible for parents to buy necessary textbooks for the education of other children in the family $(90.0 \%)$. Lack of money makes it difficult for them to purchase proper school uniforms for other children in the family $(78.8 \%)$. Parents cannot afford private education for other children because of a lack of money $(90.0 \%)$.

This result confirms the position of Roth et al. [13], who maintained that the experience of siblings of children with autism varies from family to family (Autism is a developmental disorder that directly relates to ID). She stated that when the family is affected by other factors indirectly linked to the presence of a child with autism, such as low-income or restricted leisure opportunities, or where there is a stress on the parents' relationship, this may compound the difficulties for siblings. Ashley [15] reported the study of Barak-Levy, Goldstein, and Weinstock [4]. They found that 27 parent self-reports were compared to 27 self-reports of siblings of children with disabilities and 27 self-reports of siblings of children without disabilities. Siblings of 
individuals with disabilities have been found to participate in fewer extracurricular activities than their peers. Their peers that do not have a sibling with a disability may be part of social activities, but the sibling of the individual with a disability is often involved in fewer of these types of activities. Instead, they help their siblings and have additional responsibilities in the home. Being a sibling of a child with a disability can also have an impact on the career path of the sibling without a disability. Marks, Matson, and Barraza [16] found that siblings have a desire to make improvements in the areas of services provided to individuals with disabilities.

The presence of a disabled child is capable of making other children (siblings) feel emotionally disturbed; they experience the same emotional problems (anger, guilt, and so forth) as parents of children with disabilities, which may harm their education. A substantial account indicates that nondisabled siblings are aware at an amazingly early age that their brother/sister is different in some way. As a non-disabled sibling grow older, their concern often becomes more focused on how society views them and their siblings who are disabled. This, however, influences the level of education and career choice of siblings of children with ID. It places possible issues of responsibility for financial support and, at the same time, may even stop schooling from taking care of the disabled sibling in cases that the parents may have to work to make it possible. Marks et al. [16] found that siblings have a desire to improve in the area of services provided to the individual with disability. In most cases, the inability of parents to provide needed and necessary educational services for their children with intellectual disabilities often affects their siblings' career as well.

Meadan, Stone, and Angell [19] reported mixed results on outcomes of adjustment of typically developing siblings of individuals with ID. It was reported that some siblings are positively affected, while some are negatively affected. The study results revealed that the siblings experience disadvantages due to the presence of children with ID in their family. These disadvantages included the parents having less time to spend with the siblings, decreased number of family activities, diminished financial resources, increased caregiving responsibilities placed on the intellectually disabled child, and decreased peer acceptance of siblings. All these consequently affect the education of the siblings negatively. According to Downey [9], the number of siblings is linked to educational outcomes due to resource dilution. Resource dilution states that any given family has a set number of resources, if there is only one child in the family, that child receives all those resources. In larger families, the resources must be divided up so that each child gets fewer resources. Many studies consider both the size of the siblings and birth order to examine educational outcomes as they are closely related and play an important role in educational attainment $[20$, 21].

Begum and Blacher [22] reported the result of the study on the influence of disability on the sibling educational attainment. Results show that young adults who have siblings with disability in childhood will be less likely to complete high school and would complete fewer years of education than those who do not have siblings that are disabled. It was equally reported that when one has a child with ID, siblings may take the role of caregivers or may leave school to work, thereby making it challenging to complete their education.

\section{The Impact of ID on the Access to Quality Education by Children with ID in Calabar, Cross River State Nigeria}

This study revealed that ID has significant impacts on the education of individuals with ID in Calabar, Cross River State. The findings show that the families of most respondents cannot send their children with ID to a special private school because of a lack of money (78.8\%). They cannot afford individual home teachers for the children with ID because of a lack of funds (81.8\%). Their children with ID cannot be given early intervention because of a lack of money in the family $(81.8 \%)$. They cannot afford rehabilitation services for their children with ID because of a lack of funds $(100 \%)$. Their children with ID cannot go for standard educational screening and assessment because of a lack of money $(100 \%)$. This revealed the cumulative effects of the disability on the affected individuals. The effects of the disability on the family often revolve around the child, especially if the affected family is of the low or middle class.

This result corroborates Steinmetz [23], who maintained that disparities in education have been ongoing for generations even though American Disability Acts (ADA) assures equal opportunities in education for people with disabilities and prohibits discrimination based on disability. People with disabilities remain over-represented among the poor and undereducated. Analysis of case studies in some 
developing countries like Nigeria shows that higher disability is associated with higher illiteracy. Lack of learning opportunities can affect access to education and employment opportunities, reducing the chance of income enhancement and social participation.

Several factors accounted for poor educational opportunities faced by individuals with ID. A study conducted by Zoniou-Sideri and Vlachou [5] on Greek teachers' perception of children with ID revealed that regular education teachers hold several restrictive and conflicting attitudes towards the disability. They (teachers) reported that although education of children with ID is necessary as a means of improving the way ordinary school functions and it also helps to reduce stigmatization and marginalization of this set of children. However, many school teachers reject children with ID educationally, particularly those with a severe disability. The study also indicated that a single child with ID in the classroom could cause unhealthy activities that negatively affect teaching-learning activities as perceived by the teachers.

Access to early intervention for children with ID in Calabar, Cross River State, Nigeria, is difficult. To this, Bellard, Bray, Shelton, and Clarkson [24] explained that children with ID are often rejected at early childhood education centers and schools. Also, parents experience stress as a result of a lack of resources. On the contrary, when professionals and educational settings are supportive, it is a contributing factor to the family's well-being and development of the child with a disability. A low level of achievement academically is linked to poverty, as better education provides better opportunities. However, access to basic services and opportunities for people with ID is usually limited by attitudinal, physical, and information barriers. Those barriers have a direct impact on the level of education, health, and living standard of persons with ID and their families.

\section{CONCLUSION}

With the findings of this study, it is established that ID has an impact on the family economy, and it also affects the family significantly, in most cases, negatively in Calabar, Cross River State, Nigeria. ID can lead to family poverty. The consequence of ID on the family income is enormous, affecting the quality of life of the entire family; the parents, the siblings, and the child with ID. Because of the nature of ID, most parents find it difficult to get gainful employment and adequate care for themselves and the family members.
Lack of social facility from the government, coupled with the negative impact of the disability on the time and material resources, often lead to abject poverty.

\section{RECOMMENDATION}

Federal, State, and Local governments in Nigeria should establish a social facility for the care of persons with intellectual and developmental disabilities. This will assist the parents by reducing the burden associated with the care of persons with ID and other related disorders. The government should provide free and accessible education and health care for all categories of persons with disabilities in Nigeria. Because of the challenge of care faced by parents leading to unemployment, government, corporate organisation and non-governmental organisations should embark on empowerment programmes that will make parents of children with ID self-employed. The government should encourage the employment of persons with mild ID as this will help reduce the impact of the disability on the family.

\section{REFERENCE}

[1] Kalu I. Intellectual Disability and Special Needs Education: Educational Viewpoint. Ibadan: BWright Integrated Publishers Limited.

[2] Kelly M. Understanding psychosis in individuals with intellectual disabilities. UK: Regional Support Associate 2013.

[3] Peterson L. Parenting. Different kinds of parenting Te-Ara the encyclopedia of New Zealand. Ministry of culture and heritage Nz Government 2011.

[4] Winthrop AL, Brasel KJ, Stohovic L, Paulson J, Schneeberger B, Kuhn EM. Quality of life and functional outcome after pediatric trauma. J Trauma 2005; 58(3): 468473.

https://doi.org/10.1097/01.TA.0000153940.23471.B7

[5] Zoniou-Sideri A, Vlachou A. Greek teachers' belief systems about disability and inclusive education. International Journal of Inclusive Education 2006; 10(4-5): 379-394. https://doi.org/10.1080/13603110500430690

[6] Fujiura GT. Demography of family households. American Journal on Mental Retardation 2010; 103: 225-235. https://doi.org/10.1352/08958017(1998)103<0225:DOFH>2.0.CO;2

[7] Chapman DA, Scott KG, Stanton-Chapman TL. Public health approach to the study of mental retardation. American Journal on Mental Retardation 2008; 113: 102-116. https://doi.org/10.1352/08958017(2008)113[102:PHATTS]2.0.CO;2

[8] Emerson E, Parish SL. Intellectual disability and poverty: Introduction to the special section. Journal of Intellectual \& Developmental Disability 2010; 35(4): 221-223. https://doi.org/10.3109/13668250.2010.525869

[9] Emerson E. Poverty and people with intellectual disabilities. Mental Retardation and Developmental Disabilities Research Reviews 2007; 13: 107-113. https://doi.org/10.1002/mrdd.20144

[10] Emerson E. Mothers of children and adolescents with intellectual disability social and economic situation, mental 
health status and self-assessed social and psychological impact of the child's difficulties. Intellect Disability Research 2003; 47(4/5): 385-399. https://doi.org/10.1046/j.1365-2788.2003.00498.x

[11] Van Cleave J, Gortmaker SL, Perrin JM. Dynamics of obesity and chronic health conditions among children and youth. JAMA 2010; 303(7): 623-630. https://doi.org/10.1001/jama.2010.104

[12] Simkiss DE, Blackburn CM, Felix O, Mukoro FO, Read JM, Spencer NJ. Childhood disability and socio-economic circumstances in low and middle income countries 2019; Systematic Review. BMC Pediatrics 2011; 11: 2431-11-119. https://doi.org/10.1186/1471-2431-11-119

[13] Roth I, Barson C, Hoekstra R, Pasco G, Whatson T. The Autism Spectrum in the $21^{\text {st }}$ Century: Exploring Psychology, Biology and Practice 2010.

[14] Barak-Levy Y, Goldstein E, Weinstock M. Adjustment characteristics of healthy siblings of children with autism. Journal of Family Studies 2010; 16(2): 155-164. https://doi.org/10.5172/jfs.16.2.155

[15] Ashley MA. The Experiences of Siblings of Individuals with Disabilities: A Holistic View. College of Educational. Studies Dissertations 2016. http://digitalcommons.chapman.edu/ ces_dissertations $/ 14$.

[16] Marks S, Matson A, Barraza L. The impact of siblings with disabilities on their brothers and sisters pursuing a career in special education. Research \& Practice for Persons with Severe Disabilities 2005; 30(4): 205-218. https://doi.org/10.2511/rpsd.30.4.205

[17] Batul NB. Neurological disorder, available at www.buzzle.com/articles/neurological orders. Accessed on 29/5/2013.
$[18]$

Mu'ala AE, Abas AR, Shawam SS. Psychological burden of cerebral palsy upon care givers in Erbill Governorate. The Iraqi post graduate med 2008.

[19] Meadan H, Stoner JB, Angell ME. Review of literature related to the social, emotional and behavioral adjustment of siblings of individual with autism spectrum disorder. Journal of Developmental and Physical Disabilities 2005; 22(1); 83-100. https://doi.org/10.1007/s10882-009-9171-7

[20] De Haan M. Birth order, family size and educational attainment. Economics of Education Review 2010; 29(4): 576-588.

https://doi.org/10.1016/j.econedurev.2009.10.012

[21] Downey DB. Number of siblings and intellectual development. The resource dilution explanation. American Psychologist 2001; 56(6-7): 497-504. https://doi.org/10.1037/0003-066X.56.6-7.497

[22] Begum and Blacher. The siblings' relationship of adolescents with and without intellectual disabilities. Research in Developmental Disabilities 2011; 32(5): 1580-8. https://doi.org/10.1016/..ridd.2011.01.056

[23] Steinmetz E. Americans with disabilities: 2002. Current population reports 2006; 70-107. Retrieved from: https://www.census.gov/prod/2006pubs/p70-107.pdf.

[24] Bellard K, Bray A, Shelton E, Clarkson J. Children with disabilities and the educational system. The experience of fifteen fathers. International Journal of Disability Development and Education 1997; 3: 229-241. https://doi.org/10.1080/0156655970440305

\section{DOI: https://doi.org/10.6000/2292-2598.2020.08.02.22}

(C) 2020 Adeleke et al.; Licensee Lifescience Global.

This is an open access article licensed under the terms of the Creative Commons Attribution Non-Commercial License (http://creativecommons.org/licenses/by-nc/3.0/) which permits unrestricted, non-commercial use, distribution and reproduction in any medium, provided the work is properly cited. 